\title{
Erratum zu: Regulierung des Pflegemarktes: Räumliche Fehlentwicklungen werden verstärkt
}

\author{
Tobias Just • Franziska Plößl
}

(C) Der/die Autor(en) 2020

\section{Erratum zu:}

\section{List Forum 2020 46:245-258}

https://doi.org/10.1007/s41025-020-00196-y

Der Artikel Regulierung des Pflegemarktes: Räumliche Fehlentwicklungen werden verstärkt von Tobias Just · Franziska Plößl wurde ursprünglich ohne „Open Access“ Online First auf der Internetplattform des Verlags publiziert. Nach der Veröffentlichung im Bd. 46 Heft 2 pp. 245-258 entschieden sich die Autoren nachträglich für eine „Open Access“-Veröffentlichung. Das Urheberrecht des Artikels wurde deshalb zu (C) Der/die Autor(en) 2020 geändert.

Funding Open Access funding enabled and organized by Projekt DEAL

Open Access Dieser Artikel wird unter der Creative Commons Namensnennung 4.0 International Lizenz veröffentlicht, welche die Nutzung, Vervielfältigung, Bearbeitung, Verbreitung und Wiedergabe in jeglichem Medium und Format erlaubt, sofern Sie den/die ursprünglichen Autor(en) und die Quelle ordnungsgemäß nennen, einen Link zur Creative Commons Lizenz beifügen und angeben, ob Änderungen vorgenommen wurden.

Die in diesem Artikel enthaltenen Bilder und sonstiges Drittmaterial unterliegen ebenfalls der genannten Creative Commons Lizenz, sofern sich aus der Abbildungslegende nichts anderes ergibt. Sofern das betreffende Material nicht unter der genannten Creative Commons Lizenz steht und die betreffende Handlung

Die Online-Version des Originalartikels ist unter https://doi.org/10.1007/s41025-020-00196-y zu finden.

Tobias Just $(\bowtie) \cdot$ Franziska Plöß1

IREBS Universität Regensburg, Universitätsstraße 31, 93053 Regensburg, Deutschland

E-Mail: Tobias.Just@irebs.de

Franziska Plöß1

E-Mail: franziska.ploess1@irebs.de 
nicht nach gesetzlichen Vorschriften erlaubt ist, ist für die oben aufgeführten Weiterverwendungen des Materials die Einwilligung des jeweiligen Rechteinhabers einzuholen.

Weitere Details zur Lizenz entnehmen Sie bitte der Lizenzinformation auf http://creativecommons.org/ licenses/by/4.0/deed.de. 